\title{
As Implicações da Problemática dos Resíduos Sólidos e o Advento da Lei 12.305/2010: o Aterro Sanitário do Jardim Gramacho no Município de Duque de Caxias
}

\author{
Vânia Siciliano Aieta ${ }^{1}$
}

\begin{abstract}
Os efeitos negativos das relações governamentais despidas de interesse público; a degradação ambiental nos processos de urbanização de países de desenvolvimento capitalista periférico - a urbanização da pobreza; a cultura do consumo exacerbado nas sociedades contemporâneas e a problemática dos resíduos; a política nacional dos resíduos sólidos e a lei $\mathrm{n}^{\circ}$ 12.305/2010; o caso do estado do rio de janeiro; a problemática nos municípios e suas conseqüências; as exigências do ministério público; referências.
\end{abstract}

Resumo: O presente trabalho tem por objetivo o estudo das implicações trazidas pela Nova Lei dos Resíduos Sólidos (Lei 12.305/2010), com análise de suas características, enfoques, dimensões e principais aspectos.

Expressões-Chave: Políticas Públicas - Resíduos Sólidos - Gerenciamento Integrado Gestão Integrada -Consumo Desenfreado.

Abstract: The present work aims to study the implications brought by New Solid Waste Law (Law 12.305/2010), with analysis of their characteristics, approaches, main dimensions and aspects.

Keywords: Public Policy - Solid Waste - Integrated Management - Integrated Management Consumer-Rampant

\footnotetext{
${ }^{1}$ Professora Adjunta de Políticas Públicas Urbanas do Programa de Pós-Graduação da Faculdade de Direito -UERJ
} 


\section{"A cidade não é feita de pedras mas de homens" Marsilio Ficino}

\section{OS EFEITOS NEGATIVOS DAS RELAÇÕES GOVERNAMENTAIS DESPIDAS DE INTERESSE PÚBLICO}

Após quase quarenta anos de existência, o Aterro Sanitário do Jardim Gramacho, no Município de Duque de Caxias teve seu encerramento anunciado em 2012.

Malgrado a data programada para o referido fechamento estivesse prevista para o mês de junho, foi antecipada pela Prefeitura do Rio de Janeiro para abril daquele ano, causando seríssimos problemas à Prefeitura Municipal de Duque de Caxias, que não tinha se programado para tal antecipação, resultando em quadro caótico e desesperador diante das dificuldades enfrentadas no descarte do lixo.

Ademais, quase 2.000 trabalhadores ficaram sem atividades e perspectivas com a desativação do local.

A Prefeitura do Rio de Janeiro anunciou sua decisão, com interesse em se promover positivamente na $\underline{\operatorname{Rio}+20}$, a conferência de meio ambiente da ONU que ocorreu no Rio de Janeiro em 2012 e causaria à população do Município de Duque de Caxias.

A decisão da Prefeitura do Rio de Janeiro atropelou os acordos feitos para minimizar os impactos sociais decorrentes do fechamento, segundo o próprio Conselho de Lideranças dos catadores, já que não seria possível tirar do papel todas as medidas prometidas no plano de transição.

Entre as promessas estava o uso antecipado de um fundo para garantir renda mínima aos catadores e financiar políticas de inclusão, criado a partir dos lucros obtidos com o gás metano captado no aterro. Uma parte do valor seria utilizado para estruturar as cooperativas já existentes para a coleta seletiva de Duque de Caxias, com fins de oferecer uma alternativa de trabalho sustentável para os catadores e que adequaria o município à Política Nacional de Resíduos Sólidos. Outra parte serviria para capacitar quem quisesse continuar o trabalho seletivo e indenizar os interessados em mudar de atividade.

Contudo, o que se viu foi o "caos" institucionalizado, o que levou a crença de que tal antecipação do acordo governamental estaria maculada por fins políticoeleitorais despidos do necessário interesse público que deve nortear as relações institucionais entre governantes, mesmo quando de grupos políticos opostos. 


\section{A DEGRADAÇÃO AMBIENTAL NOS PROCESSOS DE URBANIZAÇÃO DE PAÍSES DE DESENVOLVIMENTO CAPITALISTA PERIFÉRICO A URBANIZAÇÃO DA POBREZA}

A aceleração desordenada do processo de urbanização provocada pelo processo de desruralização e a ideologia do urbano como "modelo de civilidade" têm como resultado uma infraestrutura precária nas cidades que não conseguem acompanhar a velocidade de seu próprio crescimento.

Devemos levar em conta que malgrado a maior parte dos habitantes do planeta vivam nas cidades, nas áreas urbanas, a grande maioria vive em situação precária ou sem serviços urbanos básicos tais como: saneamento básico, habitação, transporte, saúde, educação, cultura e moradia.

Mas do que um "processo de urbanização" (de acordo com a ONU mais de 61\% das pessoas vivem em megalópoles), o que evidenciamos são profundas desigualdades nas sociedades contemporâneas provocadas pelas deficiências nos serviços urbanos, pois os "alijados" dos serviços vão paulatinamente se distanciando dos "agraciados" formando um abismo econômico, cultural, de saúde, da vida como um todo.

Essa violenta segregação sócio-espacial provoca a dicotomia da cidade em bolsões de pobreza e bolsões de prosperidade, pois as formas de habitação obedecem a dinâmica capitalista da acumulação criando-se asuburbanização e a metropolização.

Desse modo, de um lado da cidade, evidencia-se tudo o que há de mais lindo e melhor enquanto do outro o que há são agruras, sofrimentos, falta de serviços e desrespeito com a cidadania.

\section{A CULTURA DO CONSUMO EXACERBADO NAS SOCIEDADES CONTEMPORÂNEAS E A PROBLEMÁTICA DOS RESÍDUOS}

A questão da degradação ambiental e suas implicações com a problemática da produção desenfreada de resíduos estão intimamente vinculadas à "cultura do consumo", pois as sociedades estão profundamente dependentes de um modo de vida onde "o ter" é muito mais importante do que "o ser", pois as pessoas passam a ser avaliadas pelos objetos que possuem tais como: o celular novo, o automóvel mais 
bonito e sofisticado, a roupa de grife e nada satisfaz. Por mais que temos e consumimos, mais queremos.

Os bens já não mais são duráveis. Quando estragam, precisamos jogar tudo fora já que o conserto do aparelho é com certeza mais caro do que adquirir uma peça nova, ou seja, trata-se de uma cultura de ostentação, de esbanjamento. A satisfação pessoal desse consumo se revela com fins de afirmação do poder de aquisição e não pela necessidade.

Assim, essa cultura de desperdício se reflete no crescimento dos resíduos e o lixo passa a ser um paradigma planetário da triste realidade do que é desordenadamente descartado.

A problemática dos resíduos sólidos é responsabilidade de todos. Herdamos resíduos das gerações pretéritas e deixaremos mais e mais lixo para as gerações futuras.

Contudo, devemos ressaltar que "o lixo" guarda estreita relação com grandes interesses econômicos que estão em jogo nas sociedades.

Além da economia gerada com a reciclagem, que pode envolver a separação do lixo que não costuma ser feita pela população, o gás metano (poluente), ao ser tratado e queimado, gera energia limpa (energia produzida e energia que deixará de ser gasta), o que propicia a não emissão de gases na atmosfera, minorando o "efeito estufa", a economia de energia, geração de fonte de renda, geração de certificados de redução de poluição, que são os chamados "créditos de carbono", determinados pelo Protocolo de Kyoto; os quais podem ser objeto de comercialização com países desenvolvidos que não têm como evitar as emissões de gás, destacando-se que cada certificado desses é negociado por cerca de quinze euros no mercado internacional.

E de todos os benefícios trazidos pela prática da reciclagem, a mais relevante é, sem dúvida, a geração de empregos. $\mathrm{O}$ aproveitamento dos "catadores de lixo" é fundamental. Mais do que acabar com sua atividade, torna-se essencial a fiscalização da atividade e fornecer condições mais dignas para o trabalho que eles desenvolvem. A COPPE, por exemplo, tem um programa de incentivo às cooperativas de catadores. O que deve ser evitado são os incidentes como o do Aterro Sanitário do Jardim Gramacho, em Duque de Caxias.

\section{A POLÍTICA NACIONAL DOS RESÍDUOS SÓLIDOS E A LEI nº 12.305/2010.}

A base da Política Nacional dos Resíduos Sólidos está no desenvolvimento sustentável, conceituado como "aquele que atende às necessidades do presente sem 
comprometer a possibilidade de as gerações futuras atenderem a suas próprias necessidades".

O conteúdo de matéria orgânica no lixo brasileiro é maior do que o conteúdo orgânico em outros países. Não havia tecnologia desenvolvida para fazê-lo até recentemente, até mesmo por não haver maior interesse. Com o conhecimento de que a disponibilidade de combustíveis fósseis está com os dias contados, o uso de resíduos orgânicos passou a ser uma opção. Apesar das descobertas de petróleo do PréSal, as reservas mundiais de petróleo estão em exaustão.

Surge, portanto, a necessidade de desenvolvermos novas fontes de energia, sendo uma delas a reutilização da matéria orgânica que está nos resíduos sólidos urbanos. É por essa razão que os resíduos sólidos são um componente importante do que se entende como desenvolvimento sustentável.

A Lei $n^{\circ} 12.305 / 2010$, dentre seus objetivos, especifica as diretrizes relacionadas à gestão integrada e ao gerenciamento de resíduos sólidos, dispondo sobre as responsabilidades dos geradores e do poder público e os instrumentos econômicos aplicáveis nesse novo gerenciamento do lixo.

A Gestão Integrada de Resíduos Sólidos é o conjunto de ações voltadas para a busca de soluções para os resíduos sólidos, de forma a considerar as dimensões política, econômica, ambiental, cultural e social, com controle social e sob a premissa do desenvolvimento sustentável.

Por sua vez, o Gerenciamento de Resíduos Sólidos é o conjunto de ações exercidas, direta ou indiretamente, nas etapas de coleta, transporte, transbordo, tratamento e destinação final ambientalmente adequada dos resíduos sólidos e disposição final ambientalmente adequada dos rejeitos, de acordo com plano municipal de gestão integrada de resíduos sólidos ou com plano de gerenciamento de resíduos sólidos, exigidos na forma da Lei.

Deve-se aduzir que o tratamento dos resíduos sólidos é complexo, pois não existe apenas um meio pelo qual se efetive o tratamento de tais resíduos. A solução não é tratar única e exclusivamente com mecanização, produção de biogás, incineração ou reciclagem, mas por meio do conjunto de todas essas soluções.

Além disso, é necessário também que os problemas ocasionados em um determinado local sejam resolvidos conforme a complexidade do próprio local.

Em alguns países, por exemplo, é proibido depositar materiais não tratados em aterros. Nos países mais desenvolvidos, há uma grande quantidade de reciclagem e 
compostagem, e também se faz uso das tecnologias de transformação ou reciclagem energética de resíduos.

O fato é que o poder público, fabricantes, importadores, distribuidores ou comerciantes devem implantar a responsabilidade compartilhada pelo ciclo de vida de todo produto, estabelecendo um conjunto de atribuições individualizadas e encadeadas para minimizar o volume de resíduos sólidos e rejeitos gerados, bem como para reduzir os impactos causados à saúde humana e à qualidade ambiental decorrentes do ciclo de vida dos produtos.

Entende-se por Resíduos Sólidos todo material, substância, objeto ou bem descartado resultante de atividades humanas em sociedade, a cuja destinação final se procede, se propõe proceder ou se está obrigado a proceder, nos estados sólido ou semisólido, bem como gases contidos em recipientes e líquidos cujas particularidades tornem inviável o seu lançamento na rede pública de esgotos ou em corpos d'água, ou exijam para isso soluções técnica ou economicamente inviáveis em face da melhor tecnologia disponível, como aqueles gerados na sua residência e que são recolhidos periodicamente pelo serviço de coleta da sua cidade e também a sobra de varrição de praças e locais públicos que podem incluir folhas de árvores, galhos e restos de poda.

Por sua vez, Rejeitos são os resíduos sólidos que, depois de esgotadas todas as possibilidades de tratamento e recuperação por processos tecnológicos disponíveis e economicamente viáveis, não apresentem outra possibilidade que não a disposição final ambientalmente adequada, como os resíduos de banheiro, tais como: papel higiênico usado, absorventes femininos, camisinha e fraldas descartáveis, ou alguns resíduos de cozinha, como guardanapos sujos, restos de esponja de aço e filme plástico sujo de sangue que envolve a carne. Vale ressaltar, nesse mister, o problema dos pneus. $\mathrm{O}$ Brasil recentemente recebeu uma leva de descarte desses pneus. Não podemos, nesse sentido, deixar de destacar o problema da desigualdade imposta pelos países mais poderosos enviando essas levas de pneus para outros países.

A lei 12.305/2010 institui a obrigatoriedade de se fazer a coleta seletiva, que nada mais é que a coleta de resíduos sólidos previamente segregados conforme sua constituição ou composição.

Desse modo, coloca o Brasil em patamar de igualdade aos principais países desenvolvidos no que concerne ao marco legal e inova com a inclusão de catadoras e catadores de materiais recicláveis e reutilizáveis, tanto na Logística Reversa quando na Coleta Seletiva.

A Lei dos Resíduos Sólidos adota os padrões sustentáveis de produção e consumo, defendendo a produção e consumo de bens e serviços de forma a atender as 
necessidades das atuais gerações e permitir melhores condições de vida, sem comprometer a qualidade ambiental e o atendimento das necessidades das gerações futuras, apoiando-se no conceito de responsabilidade compartilhada pelo ciclo de vida dos produtos.

Entre os princípios consolidados no Programa Nacional dos resíduos Sólidos encontramos a prevenção e a precaução; o poluidor-pagador e o protetorrecebedor; a visão sistêmica, na gestão dos resíduos sólidos, que considere as variáveis ambiental, social, cultural, econômica, tecnológica e de saúde pública; o desenvolvimento sustentável; a ecoeficiência, mediante a compatibilização entre o fornecimento, a preços competitivos, de bens e serviços qualificados que satisfaçam as necessidades humanas e tragam qualidade de vida e a redução do impacto ambiental e do consumo de recursos naturais a um nível, no mínimo, equivalente à capacidade de sustentação estimada do planeta; a cooperação entre as diferentes esferas do poder público, o setor empresarial e demais segmentos da sociedade; a responsabilidade compartilhada pelo ciclo de vida dos produtos; o reconhecimento do resíduo sólido reutilizável e reciclável como um bem econômico e de valor social, gerador de trabalho e renda e promotor de cidadania; o respeito às diversidades locais e regionais; o direito da sociedade à informação e ao controle social e os princípios da razoabilidade e a proporcionalidade.

A partir da lei, Distrito Federal e Municípios tem até 2014 para se adaptarem à gestão integrada dos resíduos sólidos gerados nos respectivos territórios, sem prejuízo das competências de controle e fiscalização dos órgãos federais e estaduais, bem como da responsabilidade do gerador pelo gerenciamento de resíduos, conforme estabelecido na lei $12.305 / 2010$.

Os Estados devem promover a integração da organização, do planejamento e da execução das funções públicas de interesse comum relacionadas à gestão dos resíduos sólidos nas regiões metropolitanas, aglomerações urbanas e microrregiões, nos termos da lei complementar estadual prevista no $\S 3^{\circ}$ do art. 25 da Constituição Federal. Devem, ainda, controlar e fiscalizar as atividades dos geradores sujeitas a licenciamento ambiental.

Atuação do Estado deve apoiar e priorizar as iniciativas do Município de soluções consorciadas ou compartilhadas entre dois ou mais Municípios.

A União, os Estados, o Distrito Federal e os Municípios organizam e mantêm, de forma conjunta, o Sistema Nacional de Informações sobre a Gestão dos Resíduos Sólidos (Sinir), articulado com o Sinisa e o Sinima. 
Cabe aos Estados, ao Distrito Federal e aos Municípios fornecer ao órgão federal responsável pela coordenação do Sinir todas as informações necessárias sobre os resíduos sob sua esfera de competência, na forma e na periodicidade estabelecidas em regulamento.

O Estado de São Paulo, que está em melhores condições no país, cerca de $76 \%$ dos resíduos são dispostos em aterros sanitários, $14 \%$ em aterros controlados e apenas 9\% em lixões. É importante apontar, que praticamente $80 \%$ dos resíduos gerados em São Paulo se encontram nas três regiões metropolitanas do Estado, a saber, Baixada Santista, Campinas e Grande São Paulo. Devemos ter bastante atenção com essas regiões onde há uma grande densidade demográfica.

Uma região como São Paulo admite múltiplas soluções e elas devem ser todas integradas dentro de uma lógica para tratamento do problema, envolvendo inclusive as questões sociais dos catadores, ou seja, o trabalho importante que eles realizam nessa parte da reciclagem, o qual deve ser tratado de uma forma mais profissional do que amadora.

É necessário levar em conta aspectos espaciais, ambientais, de saúde, sociais, culturais e institucionais ao analisar os resíduos sólidos. No aspecto ambiental uma das nossas necessidades e definirmos as melhores alternativas a serem adotadas, onde os impactos sejam menores e que não sejam alternativas meramente tecnológicas. Um exemplo desse desafio é a produção de cerca de 11 mil toneladas de resíduos por dia no Município de São Paulo e mais de 17 mil toneladas por dia na região metropolitana de São Paulo, que, efetivamente, não nos apresenta respostas imediatas, devendo ser buscadas soluções que combinem alternativas, ainda que aparentemente limitadas.

No que se refere aos aspectos sociais, a inclusão social se impõe como um tema fundamental, devendo trazer à tona efetivamente as possibilidades que uma política pública pode promover em termos de redução de desigualdades.

No aspecto cultural, estamos todos envolvidos, ao passo que essa grande quantidade de lixo é produzido por nós mesmos. Aproximadamente $80 \%$ da população vive em áreas urbanas, ao mesmo tempo em que a geração de resíduos sólidos per capita está aumentando cada vez mais, assim como a sua complexidade e periculosidade.

Temos como desafio também as dificuldades relacionadas à lógica de gestão desses resíduos, principalmente a dificuldade de se encontrar áreas para disposição final dos mesmos e o descarte de materiais recicláveis depositados em lixões que poderiam ser utilizados. O uso insustentável dos recursos naturais é um grande problema, sendo tratado inclusive pelos mais pessimistas como uma crise. 
No Brasil, em termos proporcionais, em torno $20 \%$ desses resíduos vão para os lixões, 24\% para aterros controlados, que são lixões que passaram a ser tratados como aterros sanitários, e cerca de 57\% para aterros sanitários (ABRELPE, 2009).

$\mathrm{Na}$ mesma linha, outro elemento a ser considerado é a necessidade do gerenciamento integrado dos resíduos sólidos urbanos. Um gerenciamento inadequado somado a não existência de uma gestão metropolitana no Brasil, apesar da existência de legislação desde a década de 1970, dificultam o processo, ou seja, apesar de haver uma alta cobertura na coleta de lixo no país, os serviços de coleta seletiva e compostagem são ínfimos.

\section{O CASO DO ESTADO DO RIO DE JANEIRO}

O Governo do Estado do Rio de Janeiro divulgou que sua meta é erradicar, até 2014, todos os lixões municipais, com as 92 cidades fluminenses passando a descartar seus resíduos sólidos em aterros sanitários ou em centrais de tratamento de resíduos (CTRs), com plantas de aproveitamento energético - ou seja, transformando em energia o gás metano gerado pela decomposição do lixo. Entre eles está o "Lixão do Jardim Gramacho, em Duque de Caxias"

Um dos seus eixos principais de atuação para a erradicação dos lixões municipais até 2014, como determina a Lei Nacional de Resíduos Sólidos, seria o "Programa Lixão Zero", coordenado pela Secretaria de Estado do Ambiente (SEA), que integra o "Pacto pelo Saneamento", instituído pelo Governo do Estado, em abril de 2011, pelo Decreto $n^{\circ} 42.930$, com o objetivo de universalizar, no Estado do Rio de Janeiro, o acesso a sistemas de saneamento básico, minimizando os impactos negativos decorrentes da inexistência desses sistemas sobre a saúde da população, o meio ambiente e as atividades econômicas.

A erradicação dos "lixões" faz parte do Plano Guanabara Limpa, que se subdivide em três iniciativas para a recuperação ambiental das águas da Baía de Guanabara: o Psam (Programa de Saneamento dos Municípios do Entorno da Baía de Guanabara), com o objetivo de avançar no saneamento e na recuperação ambiental das águas da baía; o Programa Sena Limpa, uma parceria com a CEDAE e a Prefeitura do Rio para despoluir seis das principais praias do Município do Rio de Janeiro; e a ampliação do Sistema Alegria, para a construção de novos troncos coletores de esgoto e a ampliação da capacidade da Estação de Tratamento de Esgoto (ETE) da Alegria. 
Com a conclusão de etapas importantes de execução do Lixão Zero, o Governo do Estado relata ter conseguido em 2012 erradicar todos os lixões dos 15 municípios do entorno da Baía de Guanabara.

No Rio de Janeiro, em 2007, a situação dos lixões era dramática: dos 92 municípios do Estado do Rio de Janeiro, 76 descartavam seus resíduos em lixões e apenas 12 em locais remediados e controlados. Apenas quatro cidades destinavam seu lixo adequadamente para aterros sanitários.

À época, do total de 13.738 toneladas de lixo produzidas diariamente por mais de 15 milhões de habitantes do estado, apenas $4 \%$ do lixo era reciclado; $41 \%$ descartados em lixões; $36 \%$ em locais controlados; e apenas 9\% em aterros sanitários.

Em 2010, 30 municípios fluminenses depositavam seus resíduos sólidos em locais ecologicamente corretos. No entanto, isso representa apenas $11 \%$ da quantidade total do lixo gerado no estado; equivalente a 1.931 toneladas de resíduos sólidos despejados diariamente em aterros sanitários.

Outra iniciativa interessante foi a da Prefeitura do Município do Rio de Janeiro que passou a multar, no ano de 2013, as pessoas que fossem pegas jogando lixo nas ruas da cidade. A medida foi aplicada com base na Lei de Limpeza Urbana, criada há mais de dez anos.

A execução do Programa Lixão Zero tem sido importante para se avançar na melhoria da qualidade das águas da baía, reforçando as iniciativas do Governo do Estado para se atingir a meta de sanear 80\% da Baía de Guanabara até 2016 - um dos compromissos assumidos com o Comitê Olímpico Internacional (COI) para a realização das Olimpíadas do Rio.

Quanto aos desafios, vale apontar mais alguns: reduzir a geração crescente de resíduos; maximizar o reuso, a reciclagem e a recuperação energética do metano emitido nos aterros sanitários (tema relevante que começa a ser desenvolvido no Brasil, por exemplo, com as experiências da região metropolitana de São Paulo); erradicar os lixões como já mencionado; recuperar as áreas degradadas e contaminadas (questão essa fundamental que talvez no Estado de São Paulo esteja mais sob controle); implantar a coleta seletiva com inclusão de catadores; e obter sustentabilidade financeira.

Para a execução do Programa Lixão Zero, os esforços da Superintendência de Políticas de Saneamento, da SEA, se dividiram em duas linhas de atuação: um desenvolvimento um Plano Estadual de Gestão Integrada de Resíduos Sólidos (Pegirs) e as ações para a erradicação dos lixões no Estado do Rio de Janeiro. 
O Plano Estadual de Gestão Integrada de Resíduos Sólidos (Pegirs) se iniciou com a assinatura de um convênio (MMA/SRHU $n^{\circ} 10 / 2007$ ) que estabeleceu a meta original de elaborar proposta focando em soluções regionalizadas para o destino final dos resíduos sólidos urbanos.

Desde então, foram realizados diagnósticos dos sistemas de gestão dos resíduos sólidos dos 92 municípios do estado, além de ações para a criação e implementação dos consórcios intermunicipais para gestão e tratamento adequado do lixo urbano, tendo como referência a Lei 11.107, de 06 de abril de 2005, e seu decreto de regulamentação (Decreto 6.017 de 17 de janeiro de 2007).

Com base na proposta de regionalização e nos arranjos intermunicipais que foram sendo configurados a partir de 2007, deu-se início à implantação em todo o estado de aterros sanitários ou de centrais de tratamento de resíduos sólidos (CTRs), públicos ou privados, além de ações para a remediação dos lixões municipais.

Para garantir o atendimento da Política Nacional de Resíduos Sólidos (PNRS) e seu decreto de regulamentação (Lei 12.305 de 02 de agosto de 2010 e Decreto 7.404 de 23 de dezembro de 2010), a SEA e o Ministério do Meio Ambiente estão revisando o escopo dos trabalhos previstos originalmente no convênio. Prevê-se que em breve seja concluído o Plano Estadual de Resíduos Sólidos do Estado do Rio de Janeiro (PERS/RJ).

\section{A PROBLEMÁtICA NOS MUNICÍPIOS E SUAS CONSEQÜÊNCIAS}

Nos municípios o que grupo responsabilizados pela gestão dos resíduos Sólidos deve primeiramente se informar sobre a lei que instituiu a Política Nacional de Resíduos Sólidos (Lei 12.305/10) e o seu decreto regulamentador (Decreto 7.404/10), além de verificar a existência de legislação estadual e municipal sobre o assunto.

Conforme afirmado anteriormente, a aprovação da Política Nacional de Resíduos Sólidos (PNRS) representa um grande avanço para o País. O conhecimento da lei também possibilita entender as responsabilidades dos municípios e dos geradores, sendo uma oportunidade para trilhar novos caminhos em prol da melhoria do sistema como um todo.

Alguns estados, como Rio de Janeiro e São Paulo, já possuíam a sua própria Política Estadual de Resíduos Sólidos ou planos nessa área. Quanto aos municípios, alguns já têm normas a esse respeito. Podem ser planos específicos ou elaborados em 
conjunto com os planos de saneamento. Há, ainda, os que adotam legislações que chegam a ser até mais restritivas que as próprias metas do Plano Nacional de Resíduos para os Municípios. Por isso, no caso de normas preexistentes, é sempre preciso checar a compatibilidade delas com o PGIRS, para que o município não incorra em ilegalidade.

Uma vez que a PNRS exige uma visão sistêmica, torna-se estratégico que, além da secretaria responsável pela gestão de resíduos, também componham o grupo gestor as demais secretarias afins, que lidem com aspectos sociais, de meio ambiente, trabalho, educação, cultura, tecnologia, economia e saúde pública.

Importante é conhecer a situação orçamentária do município, a Lei Orçamentária Anual (LOA) e a Lei de Diretrizes Orçamentárias (LDO), o quanto já foi investido de recursos em determinado projeto de gestão de resíduos, contratos em vigência e, principalmente, a possibilidade de aporte de recursos suplementares, no âmbito estadual ou federal, e outras fontes de financiamento para a implantação do plano.

Deve ainda ser elaborado um diagnóstico que tem como função apontar a caracterização e a quantidade de resíduos sólidos gerados, bem como o seu destino nas diferentes regiões do município, atendendo ao conteúdo mínimo definido no Artigo 19 da PNRS. E, para que um diagnóstico chegue o mais próximo possível da representação da realidade, seus dados devem ser coletados a partir de fontes diversas, priorizando a coleta de informações em campo e se valendo de relatórios produzidos por outros setores governamentais, como IBGE e IPEA, não governamentais e acadêmicos.

Dessa forma, devem ser consultados: a população, por meio de audiências públicas, oficinas e fóruns; a Secretaria de Saúde, que pode dispor de dados sobre consultas e internações ocasionadas por doenças de origem sanitária ou pontos de acúmulo de resíduos que ocasionem focos de vetores de doenças; a secretaria responsável pela limpeza urbana, que pode fornecer dados sobre o atual sistema de coleta de resíduos; a Secretaria de Educação ou a Secretaria de Meio Ambiente, que podem ter programas ou histórico das ações de educação ambiental; o Departamento de Serviço Social, que pode já ter os dados ou iniciar um trabalho de cadastramento dos catadores de materiais recicláveis.

A partir das oportunidades e desafios levantados no diagnóstico, deve-se formular o Plano de Gestão. Nele devem constar as diretrizes, metas e estratégias de curto, médio e longo prazos para cada tipo de resíduo, seja ele de responsabilidade da prefeitura municipal, dos munícipes ou de outros geradores.

As soluções apresentadas no Plano de Gestão devem obedecer, minimamente, à seqüencia de metas e estratégias estabelecidas no Artigo 19 da Lei 12.305/2010, que define desde a forma de não geração até a disposição final adequada dos rejeitos para 
municípios de mais de 20 mil habitantes. Cidades com menos de 20 mil habitantes podem apresentar Planos de Gestão com conteúdos mais simplificados, de acordo com o Decreto 7404/2010.

Os principais aspectos a serem levantados em um diagnóstico são: o marco legal regulatório, fazendo o levantamento e o estudo das legislações federais, estaduais e municipais, com análise dos caminhos já apontados por elas e necessidades de mudanças; aspectos de geração e disposição, qualificando e quantificando os tipos de resíduos produzidos em cada um dos sistemas presentes na cidade, visto que esses dados formarão a base para a elaboração de um bom Plano Integrado, que favorecerá a execução do sistema e o gerenciamento específico de cada unidade de gestão do município; aspectos econômicos, analisando as possibilidades de desenvolver novos processos, desenhos de produtos e embalagens mais eficientes, e tecnologia de recuperação dos resíduos já existente; aspectos sociais, uma vez que mais do que uma prerrogativa da lei, a inclusão social dos catadores de materiais recicláveis, por exemplo, é o caminho para o sucesso do futuro Programa de Coleta Seletiva, que incluirá contribuição ambiental e social, além de geração de trabalho e renda no município; e possíveis parceiros, ao passo que é fundamental o envolvimento dos diferentes atores sociais em todas as fases do processo de reciclagem.

Ressalte-se que depois de aprovado, o Plano de Gestão Integrada de Resíduos deve ser implantado com a participação dos representantes dos setores por ele responsáveis, sendo realizadas ações de capacitação técnica, voltadas à implementação e à operacionalização, além de programas de educação ambiental, que promovam a não geração, a redução, a reutilização e a reciclagem de resíduos sólidos, conforme especificado na PNRS.

Outra diligência que também permitirá o acompanhamento da execução do plano é a avaliação periódica. Por meio de indicadores apresentados a cada revisão, será possível tomar ações corretivas, e até preventivas, quando necessário.

\section{AS EXIGÊNCIAS DO MINISTÉRIO PÚBLICO}

O Ministério Público de alguns Estados está exigindo das prefeituras a apresentação de planos para o cumprimento da política nacional de coleta e reciclagem de resíduos sólidos. Os municípios têm até agosto para apresentar suas estratégias de gestão do lixo para o governo federal. Caso contrário, não receberão recursos para a instalação de aterros sanitários e a implantação da coleta seletiva. 
O interessante nesse acompanhamento é que ele permitirá aos promotores traçar uma estratégia para forçar os municípios a cumprir a lei, que não estabelece punições, mas pode propor termos de ajustamento de conduta (TACs) ou mesmo ações contra prefeituras e prefeitos.

Os planos municipais devem levar em consideração que, diferentemente das demais normas ambientais, a Lei $\mathrm{n}^{\circ} 12.305$ impõe a responsabilidade compartilhada entre fabricantes, comerciantes, consumidores e governo em relação à destinação e reciclagem de produtos comercializados.

Essa pressão dos MPs estaduais é importante para a adoção de políticas de resíduos sólidos pelos municípios, visto que muitas prefeituras alegam que não têm recursos suficientes para implementá-las e que precisam da ajuda das empresas ao passo que os empresários dizem que necessitam de infraestrutura para executar seus planos de gestão de resíduos. Se o MP não intervir na implementação da PNRS, dificilmente elas serão cumpridas.

No Rio de Janeiro, o MP já abriu aproximadamente 170 inquéritos civis para a implementação da política nacional de resíduos sólidos.

Os promotores do Espírito Santo estão mais adiantados. Já foram firmados alguns termos de ajustamento de conduta para que sejam adotadas medidas para corrigir, minimizar, neutralizar e prevenir degradações ambientais causadas pela destinação inadequada de resíduos sólidos, inclusive de acordo com a política nacional.

No Judiciário, os promotores têm utilizado a Lei $\mathrm{n}^{\circ} 12.305$ apenas para reforçar seus argumentos em ações propostas contra prefeituras com base em legislações estaduais sobre resíduos sólidos, na Lei de Crimes Ambientais ou na Lei Nacional de Saneamento Básico.

O MP do Paraná já usou a política nacional de resíduos sólidos em ações de improbidade administrativa propostas contra os prefeitos de Paranaguá e Jacarezinho. Esses processos foram iniciados em 2008 por suposto descumprimento da Lei de Saneamento Básico.

Em caso de condenação, a pena pode chegar à perda do cargo e à suspensão dos direitos políticos dos prefeitos. Vale advertir que estamos diante também de um indesejável quadro de "diabolização dos gestores" que fazem, muitas vezes, o que podem fazer. Contudo, o Parquet tem por hábito impor desafios hercúleos aos prefeitos impondo aos mesmos uma ambiência de ameaça constante de punição que pouco contribui para avanços significativos. 
Malgrado o prazo final para que Estados e Municípios se adaptem a estes moldes seja 2014, o fato é que o Governo Federal não pode deixar essa responsabilidade totalmente para os municípios e seus prefeitos. Faz-se necessário incrementar uma verdadeira EDUCAÇÃO POLÍTICA DA POPULAÇÃO no sentido de conscientizar as pessoas para o correto descarte do lixo.

Devemos tomar cuidado para que as medidas de proteção ambiental não abracem uma lógica neoliberal conservadora de "higienização urbana", esquecendo-se das pessoas que fazem parte das cidades, ressaltando a estética em detrimento do atendimento ao princípio magno da dignidade da pessoa humana, pois isso seria inadmissível em uma ordem verdadeiramente democrática.

\section{REFERÊNCIAS}

COUTINHO, Ronaldo. A urbanização da pobreza e a lógica do capital. IN:

COUTINHO, Ronaldo \& AHMED, Flávio. Cidade, Direito e Meio Ambiente:

perspectivas críticas. Rio de Janeiro, Editora Lumen Juris, 2011. pp. 95-126, passim.

OKADA, Denise Setsuko. A urbanização da pobreza e a lógica do capital.

IN: COUTINHO, Ronaldo \& AHMED, Flávio. Cidade, Direito e Meio Ambiente: perspectivas críticas. Rio de Janeiro, Editora Lumen Juris, 2011. pp. 95-126, passim.

PORTO GONÇALVES, Carlos Walter. A Globalização da Natureza e a Natureza da Globalização. Rio de Janeiro: Civilização Brasileira, 2006, passim. 